\title{
Exposure-response analysis of endoxifen serum concentrations in early-breast cancer
}

\author{
Anabel Beatriz Sanchez-Spitman ${ }^{1,2}$ (D) Dirk-Jan A. R. Moes ${ }^{1,2} \cdot$ Jesse J. Swen ${ }^{1,2} \cdot$ Vincent O. Dezentjé $^{3}$. \\ Diether Lambrechts ${ }^{4,5} \cdot$ Patrick Neven $^{6} \cdot$ Hans Gelderblom ${ }^{2,7} \cdot$ Henk-Jan Guchelaar ${ }^{1,2}$
}

Received: 28 January 2020 / Accepted: 19 May 2020 / Published online: 29 May 2020

(c) The Author(s) 2020

\begin{abstract}
Purpose Tamoxifen is part of endocrine therapy in breast cancer treatment. Studies have indicated the use of endoxifen concentrations, tamoxifen active metabolite, to guide tamoxifen efficacy. Three endoxifen thresholds have been suggested $(5.9 \mathrm{ng} / \mathrm{ml}, 5.2 \mathrm{ng} / \mathrm{ml}$ and $3.3 \mathrm{ng} / \mathrm{ml}$ ) for therapeutic drug monitoring (TDM). Our aim was to validate these thresholds and to examine endoxifen exposure with clinical outcome in early-breast cancer patients using tamoxifen.

Methods Data from 667 patients from the CYPTAM study (NTR1509) were available. Patients were stratified (above or below), according to the endoxifen threshold values for tamoxifen efficacy and tested by Cox regression. Logistic regressions to estimate the probability of relapse and tamoxifen discontinuation were performed.

Results None of the thresholds showed a statistically significant difference in relapse-free survival: $5.2 \mathrm{ng} / \mathrm{ml}$ threshold: hazard ratio (HR): $2.545,95 \%$ confidence interval (CI) $0.912-7.096, p$ value: $0.074 ; 3.3 \mathrm{ng} / \mathrm{ml}$ threshold: HR: 0.728 ; $95 \%$ CI $0.421-1.258, p$ value: 0.255 . Logistic regression did not show a statistically significant association between the risk of relapse (odds ratio (OR): 0.971 (95\% CI 0.923-1.021, $p$ value: 0.248 ) and the risk for tamoxifen discontinuation (OR: 1.006 95\% CI 0.961-1.053, $p$ value: 0.798 ) with endoxifen concentrations.

Conclusion Our findings do not confirm the endoxifen threshold values for TDM nor does it allow definition of a novel threshold. These findings indicate a limited value of TDM to guide tamoxifen efficacy.
\end{abstract}

Keywords Endoxifen $\cdot$ TDM $\cdot$ Tamoxifen $\cdot$ Clinical outcome $\cdot$ Breast cancer

Henk-Jan Guchelaar

h.j.guchelaar@lumc.nl

1 Department of Clinical Pharmacy and Toxicology, Leiden University Medical Center, Albinusdreef 2, 2300 RC Leiden, The Netherlands

2 Leiden Network for Personalised Therapeutics, Leiden University Medical Center, Leiden, The Netherlands

3 Department of Medical Oncology, Netherlands Cancer Institute/Antoni van Leeuwenhoek, Amsterdam, The Netherlands

4 Center for Cancer Biology, VIB, Leuven, Belgium

5 Laboratory for Translational Genetics, Department of Human Genetics, KU Leuven, Leuven, Belgium

6 Department of Medical Oncology, University Hospital Leuven, Leuven, Belgium

7 Department of Medical Oncology, Leiden University Medical Center, Leiden, The Netherlands

\section{Introduction}

In the therapy of breast cancer, tamoxifen has been successfully prescribed for more than 40 years as adjuvant endocrine therapy in early-breast cancer patients [1]. In the current clinical guidelines, tamoxifen is recommended for premenopausal female patients as a 5-year monotherapy [2, $3]$, whereas for postmenopausal women a switch to an aromatase inhibitor is advised after two of 3 years of tamoxifen treatment $[2,3]$.

Tamoxifen is a selective estrogen receptor modulator that is characterised by a complex metabolism. Initially, tamoxifen is metabolised into its primary metabolites, $\mathrm{N}$-desmethyl-tamoxifen (NDM-tamoxifen) and 4-hydroxytamoxifen, whilst a second conversion from NDM-tamoxifen and 4-hydroxy-tamoxifen leads to endoxifen (Fig. 1).

Among all tamoxifen metabolites, 4-hydroyx-tamoxifen and endoxifen are recognized as the active metabolites of tamoxifen. Both tamoxifen metabolites do have similar 


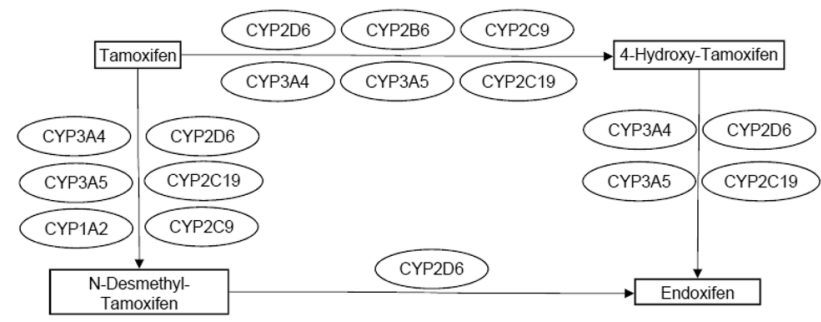

Fig. 1 Tamoxifen metabolism

anti-estrogenic activity [4], being 30 to 100 times higher than the anti-estrogenic activity of the parent compound tamoxifen. However, endoxifen is considered the most important and the principal metabolite of tamoxifen metabolite, mostly because endoxifen is detected in 5 to 10 fold higher concentrations than 4-hydroxy-tamoxifen [5]. Interestingly, endoxifen's mechanism of action might also differ from tamoxifen and its other metabolites, since it has been suggested to be concentration-dependent [6].

In the search for a more effective manner to predict tamoxifen efficacy in early-breast cancer patients, therapeutic drug monitoring (TDM) of endoxifen concentrations has been proposed [7]. To date, only a few studies have investigated the association between endoxifen concentrations and clinical outcomes in breast cancer patients receiving adjuvant tamoxifen. In the first research exploring this association, Madlensky et al. reported a threshold for endoxifen of $5.97 \mathrm{ng} / \mathrm{ml}$ [8]. According to these results, patients with an endoxifen concentration above this cutoff value, had at least a $26 \%$ decreased probability of breast cancer recurrence in comparison with patients with an endoxifen concentration below this threshold (adjusted hazard ratio (HR): 0.76, 95\% confidence interval (CI) 0.55-1.00). For this retrospective analysis, the authors analysed a subset of 1370 women who were previously enrolled in the Women's Healthy Eating and Living (WHEL) study and patients were stratified in five different endoxifen concentration groups. In this study, only blood samples after at least 4 months of tamoxifen treatment were retrieved.

Likewise, Saladores et al. reported a comparable threshold value for endoxifen concentration of $5.2 \mathrm{ng} / \mathrm{ml}$ in a study cohort of 306 premenopausal women [9]. In this study, patients were again divided into quartiles or four groups according to their endoxifen concentration and only when a comparison between the group with low endoxifen concentrations $(<5.2 \mathrm{ng} / \mathrm{ml}$ or $<14.15 \mathrm{nM})$ and the group with high endoxifen concentrations ( $>12.9 \mathrm{ng} / \mathrm{ml}$ or $>35 \mathrm{nM}$ ) was made, a worsened clinical outcome, expressed as distant relapse-free survival, was observed (adjusted HR: 1.94; 95\% CI 1.04-4.14).

In another study by Helland and colleagues, a much lower endoxifen threshold concentration of $3.3 \mathrm{ng} / \mathrm{ml}$ ( or $9 \mathrm{nM}$ ) was related to poorer survival outcome [10] (adjusted HR: 3.70; 95\% CI 1.03-13.25; $p$ value: 0.029). In this study, 99 pre- and postmenopausal patients were investigated, with a median follow-up of 13.9 years. An important advantage of this study compared to other studies is the use of 4-hydroxytamoxifen concentrations for which a threshold for efficacy was reported. According to the authors, patients with a concentration of 4-hydroxy-tamoxifen below $3.26 \mathrm{nM}$, had worsened clinical outcomes when compared with those patients with higher 4-hydroxy-tamoxifen concentrations (Adjusted HR: 3.56; 95\% CI 1.14-11.07; $p$ value: 0.020).

Although all these studies focused on finding the lowest concentration levels of endoxifen associated with clinical outcome, Love and colleagues suggested an upper limit of $70 \mathrm{ng} / \mathrm{ml}$ for endoxifen concentrations above which patients might have a higher chance of cancer relapse [11]. Although these findings were obtained in a nested case-control cohort of only 48 patients, authors did not report a minimal endoxifen concentration for tamoxifen efficacy. In the same line, Groenland et al. did not find statistically significant differences of clinically important toxicities among patients with endoxifen concentration levels above $25 \mathrm{ng} / \mathrm{ml}$ compared to patients with lower endoxifen concentrations [12]. In contrast to Groenland, another study by Helland and colleagues [13] suggest that higher tamoxifen metabolite concentrations, may be associated with adverse effects, such as vaginal dryness. Of note, endoxifen concentration was not related to any of the analysed adverse effects.

All of these studies might also have limitations, such as the fact that their outcomes and conclusions were based on the retrospective cohorts of patients. An important difference across these studies are the number of patients and the different study populations. For instance, Saladores analysed only premenopausal women [9], whilst Helland [10] and Madlensky [8] studied both pre- and postmenopausal patients.

In contrast to these studies, a recent prospective study by Neven et al. in which 297 breast cancer patients receiving tamoxifen in the metastatic and neoadjuvant setting failed to identify a relationship between improved survival outcome and endoxifen concentrations [14]. In the same line, another recent research also in the metastatic scenario by Takano and colleagues [15] did not detect any association between endoxifen concentration levels and tamoxifen efficacy. In this study, authors enrolled 186 Japanese women between December 2012 and March 2016 diagnosed with stage IV breast cancer who received tamoxifen as first-line of treatment. In this study, authors concluded that no differences in the survival outcome, defined as progression-free survival, were observed (HR: $0.75,95 \%$ CI 0.50-1.14).

Another recently published study performed in the adjuvant setting, followed 667 women diagnosed with early-breast cancer and treated with tamoxifen as adjuvant endocrine therapy were also evaluated. In this case, 
the putative association between $C Y P 2 D 6$ genotypes and endoxifen concentrations with relapse-free survival was also investigated, but no differences in survival outcomes were obtained. Therefore, these outcomes were in line with to those of Neven and colleagues [14] and Takano et al. [15].

Owing to the differences across studies, the use of TDM of endoxifen for guiding individual tamoxifen treatment in the clinical practice is still not generally implemented [7] and disagreements in the interpretations regarding the conclusions of these studies are present [16-19].

Therefore, we aimed to examine the exposure-response relationship of endoxifen in a large prospective cohort of women with early-breast cancer using tamoxifen.

\section{Materials and methods}

\section{Study population and design}

To investigate the association of endoxifen concentrations with clinical outcomes, serum samples and clinical data, such as follow-up and clinical characteristics, from the CYPTAM cohort (NTR1509) of early-breast cancer patients treated with adjuvant tamoxifen were analysed. This study population of 667 patients was recruited between February 2008 and December 2010 in the Netherlands and Belgium. Shortly, the co-primary objectives of this observational study were to evaluate the association of endoxifen serum concentrations and CYP2D6 predicted phenotypes with breast cancer relapse. According to the inclusion criteria, only female early-breast cancer patients receiving $20 \mathrm{mg}$ QD adjuvant tamoxifen could be included. In addition, patients who were already using tamoxifen but for less than 12 months from the start of the treatment were eligible. In all cases, a serum sample from each included patient for measuring the concentrations of tamoxifen, NDM-tamoxifen, 4-hydroxy-tamoxifen and endoxifen were retrieved at least 2 months after the start of the treatment with tamoxifen to assure steady-state concentrations. Of note, 24 patients of this study population participated in another separated study in which a temporary ( 2 months) increase in tamoxifen doses were used. However, we did not take the temporary increase of the dose into account as we considered it as neglectable as compared to the median duration of standard dose of daily $20 \mathrm{mg}$ of tamoxifen [20].

All patients gave written informed consent. The Institutional Review Board of the Leiden University Medical Center approved the study protocol. A more detailed description of CYPTAM has been published previously $[16,21,22]$.

\section{Study objectives}

The primary objective of the current analysis was to examine the impact of the all proposed threshold for endoxifen serum concentrations from the literature $(5.9 \mathrm{ng} / \mathrm{ml}[8], 5.2 \mathrm{ng} / \mathrm{ml}$ [9] and $3.3 \mathrm{ng} / \mathrm{ml}$ [10]) and the median endoxifen serum concentration $(10.3 \mathrm{ng} / \mathrm{ml})$ in a prospectively designed study with a large cohort of female breast cancer patients using tamoxifen and who previously were enrolled in the CYPTAM study [16]. This median concentration value for endoxifen was selected in order to uniformly assess the exposure to anti-estrogenic activity of endoxifen in this study population. In addition, patients were categorized in quartiles, according to their endoxifen concentration levels. Of note, outcomes of the survival analysis for the endoxifen threshold of $5.9 \mathrm{ng} / \mathrm{ml}$ and endoxifen as a continuous variable (accounting from the start of tamoxifen treatment) were already reported as an exploratory analysis in the CYPTAM study [16]. In the current manuscript, they are presented again for a comparison to all the thresholds for endoxifen concentrations available in the literature.

For the purpose of this study, relapse-free survival was chosen as the primary endpoint. RFSt was described as the time from initiation of tamoxifen treatment until locoregional or distant relapse or secondary breast cancer. If a patient switched to an aromatase inhibitor after 2 or 3 years of tamoxifen treatment, censoring at the time of tamoxifen discontinuation occurred, as previously also analysed in the CYPTAM study [16].

The secondary objectives were to investigate the effect of endoxifen concentrations and its relationship with the probability of breast cancer relapse and of tamoxifen discontinuation in the same study population.

\section{Measurement of tamoxifen and its metabolites concentrations}

Tamoxifen, NDM-tamoxifen, 4-hydroxy-tamoxifen and endoxifen through concentrations were measured in serum at steady state ( $>2$ months after start of tamoxifen).

Concentrations of tamoxifen and its three metabolites were quantified by a high-performance liquid chromatography-tandem mass spectrometry (HPLC-MS/MS). This method was developed and validated according to the EMA bioanalytical method validation guideline by the Clinical Pharmacy and Toxicology Department of Leiden University Medical Center in line with a previously described bioanalytical method [23].

\section{Statistical analysis}

For the primary objective, all patients were divided in two groups according to their endoxifen steady-state 
concentrations (Endoxifen threshold $5.9 \mathrm{ng} / \mathrm{ml}: \leq 5.9 \mathrm{ng} /$ $\mathrm{ml}$ vs $>5.9 \mathrm{ng} / \mathrm{ml}$; Endoxifen threshold $5.2 \mathrm{ng} / \mathrm{ml}: \leq 5.2 \mathrm{ng} /$ $\mathrm{ml}$ vs $>5.2 \mathrm{ng} / \mathrm{ml}$; Endoxifen threshold $3.3 \mathrm{ng} / \mathrm{ml}: \leq 3.3 \mathrm{ng} /$ $\mathrm{ml}$ vs $>3.3 \mathrm{ng} / \mathrm{ml}$; Median endoxifen concentration $10.3 \mathrm{ng} /$ $\mathrm{ml}: \leq 10.3 \mathrm{ng} / \mathrm{ml} \mathrm{vs}>10.3 \mathrm{ng} / \mathrm{ml}$ ). To evaluate differences of the patient's demographics across groups, $\chi 2$ tests or $t$ statistics or Mann-Whitney tests was performed used, depending on the type of data.

For the analysis of the primary objective, Cox regression was performed to analyse whether RFSt differed through all the four groups (Hazard Ratios; HR). For this analysis, uniand multivariable analysis applied. In the case of univariable analysis, when a $p$ value $<0.1$ was obtained, this covariate was adopted in the multivariable analysis. Yet, the following covariates were fitted in the multivariable analysis due to their clinical relevance: tumour and nodal stage, histological classification and grade and Her2 receptor status.

For the secondary objective, a logistic regression analysis was performed. Because our aim was to depict how the probability of breast cancer recurrence varies according to endoxifen concentrations, the use of a logistic model was required. In the same manner, another logistic regression was performed to evaluate the chance of discontinuation of tamoxifen treatment related to endoxifen concentrations. In this case, treatment discontinuation with tamoxifen due to side effects was used as a proxy to estimate the effect of side effects. For both analyses, odds ratios (OR) were calculated in order to determine the effect size. All statistical analyses were performed with IBM SPSS for Windows, Version 23.0 and R studio Version 1.0.456 and package R (v3.4.4). Also, statistical significance was accepted for $p$ values below 0.05 .

\section{Results}

\section{Study population}

In total, 667 breast cancer patients who were receiving adjuvant tamoxifen were included in the CYPTAM study. A more comprehensive overview of the demographic characteristics is presented elsewhere [16, 21, 22, 24].

For this study, patients were categorized in the different groups depending on their endoxifen serum concentration according to the different proposed endoxifen thresholds $(5.9 \mathrm{ng} / \mathrm{ml}, 5.2 \mathrm{ng} / \mathrm{ml}, 3.3 \mathrm{ng} / \mathrm{ml}$ and median $(10.3 \mathrm{ng} / \mathrm{ml})$. Of note, patients with endoxifen concentrations below the $5.9 \mathrm{ng} / \mathrm{ml}, 5.2 \mathrm{ng} / \mathrm{ml}, 3.3 \mathrm{ng} / \mathrm{ml}$ and $10.3 \mathrm{ng} / \mathrm{ml}$ threshold were $139(21 \%), 112(16.9 \%), 49(7.4 \%)$ and $332(50.2 \%)$ patients, respectively. At baseline, no differences in clinical characteristics were observed $(p>0.05)$ (Table 1), with the exception of the progesterone receptor status (positive or negative) and axillar surgery (sentinel node procedure only or axillary lymph node dissection) in the group of endoxifen threshold of $3.3 \mathrm{ng} / \mathrm{ml}$. The median follow-up was 6.8 years (range 0.33-9.34 years) and the total event rate during tamoxifen therapy was $8.5 \%$. As previously reported [16], approximately $66 \%$ of the enrolled patients started tamoxifen as endocrine therapy and switched to an aromatase inhibitor after two or three years of endocrine therapy.

\section{Analysis of endoxifen serum concentrations and the relationship with clinical outcome (RFSt)}

The association between endoxifen serum concentrations, examined as continuous variable, with clinical outcome, evaluated as RFSt since the exposure to endoxifen (did not yield any significant differences in both uni- (hazard ratio (HR): $0.988,95 \%$ confidence interval (CI) 0.944-1.035, $p$ value: 0.613 ) and multivariable analysis (adjusted HR: $0.985,95 \%$ CI $0.938-1.034, p$ value: 0.541 ) (Table 2). Interestingly, these results minimally vary from the previously described outcomes, in which the reported exposure was assessed from the time of enrolment [16]. At the same time, dividing all patients according to their endoxifen concentration in quartiles, did not change these outcomes (Table 2). For the primary objective of this study, the following proposed analyses were to estimate the usefulness of the different endoxifen threshold concentrations from the literature $(5.9 \mathrm{ng} / \mathrm{ml}, 5.2 \mathrm{ng} / \mathrm{ml}$ and $3.3 \mathrm{ng} / \mathrm{ml})$ and the endoxifen median concentration $(10.3 \mathrm{ng} / \mathrm{ml})$ of the CYPTAM study. A total of 4 groups were made, according to the endoxifen serum concentrations: below and above of $5.9 \mathrm{ng} / \mathrm{ml}$, below and above of $5.2 \mathrm{ng} / \mathrm{ml}$, below and above of $3.3 \mathrm{ng} / \mathrm{ml}$ and below and above of $10.3 \mathrm{ng} / \mathrm{ml}$.

In the first analysis (below and above of $5.9 \mathrm{ng} / \mathrm{ml}$ ), no statistically significant differences were found in either the uni-variable (HR: $1.382,95 \%$ CI $0.652-2.928, p$ value: 0.399 ) or multivariable analysis (adjusted HR: $1.426,95 \%$ CI 0.666-3.053, $p$ value: 0.361 ). Similarly, using the endoxifen thresholds of $5.2 \mathrm{ng} / \mathrm{ml}$ and $3.3 \mathrm{ng} / \mathrm{ml}$ also did not relate to improve these outcomes, since the multivariate Cox analysis of HR 2.545 (95\% CI 0.912-7.096, $p$ value: 0.074 ) and HR 2.992 (95\% CI 0.410-21.822.216, $p$ value: 0.280 ) also failed to find an association, respectively. Also, dividing patients according to the endoxifen concentration and using the median endoxifen concentrations $(10.3 \mathrm{ng} / \mathrm{ml})$ of the CYPTAM study as cutoff point, were not associated with RFSt (univariate analysis: HR: 0.803, 95\% CI 0.472-1.365, $p$ value:0.418; adjusted HR: $0.728,95 \%$ CI $0.421-1.258, p$ value: 0.255 ) (Table 2 ).

In accordance with the Cox regression analysis, none of the Kaplan-Meier analyses (log-rank) using any of the four endoxifen concentrations differed significantly $(5.9 \mathrm{ng} / \mathrm{ml}: p$ value: $0.396 ; 5.2 \mathrm{ng} / \mathrm{ml}: p$ value: $0.083 ; 3.3 \mathrm{ng} / \mathrm{ml} ; p$ value: $0.139 ; 10.3 \mathrm{ng} / \mathrm{ml}: p$ value: 0.417 ) (Fig. 2). 


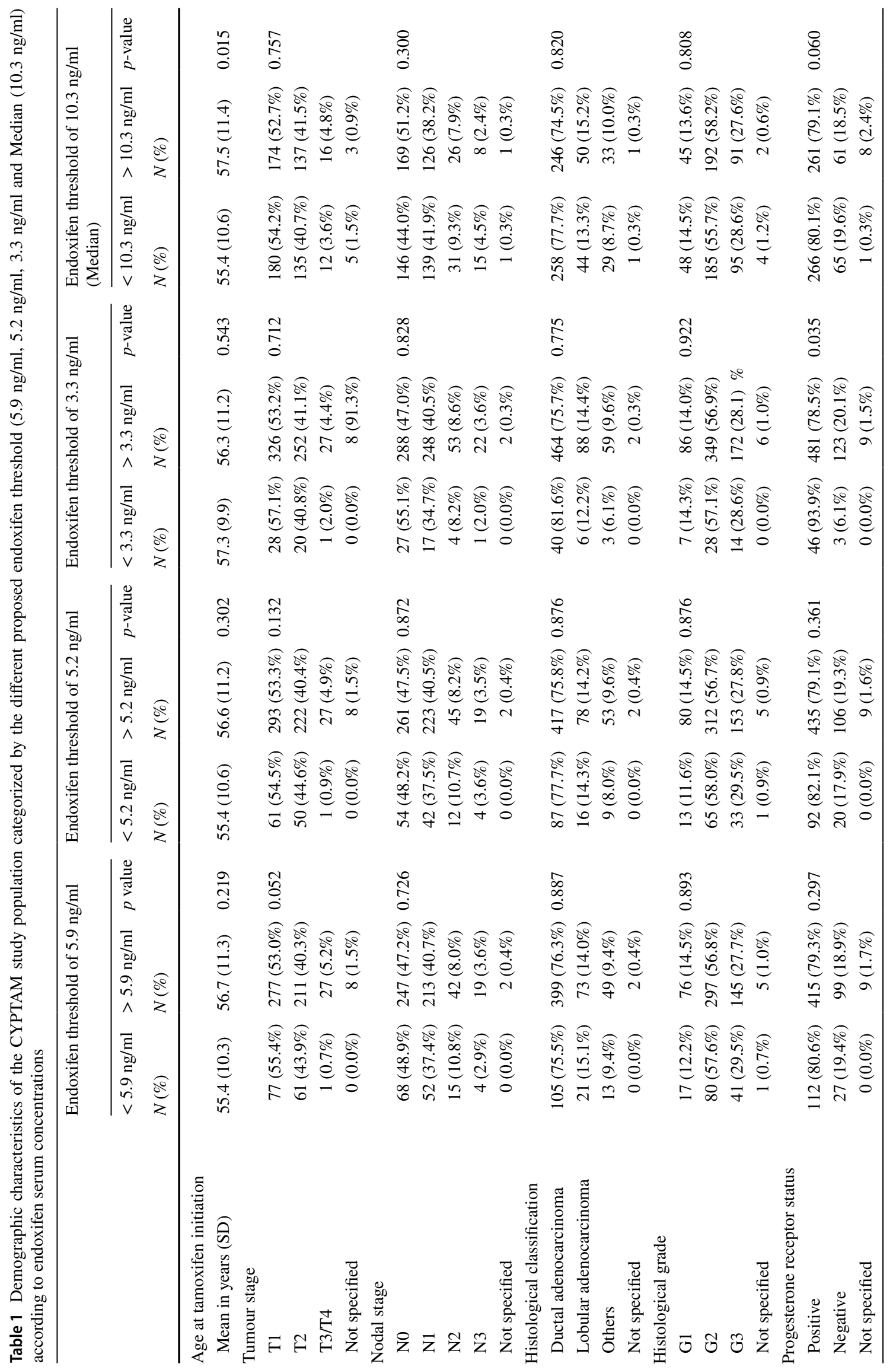




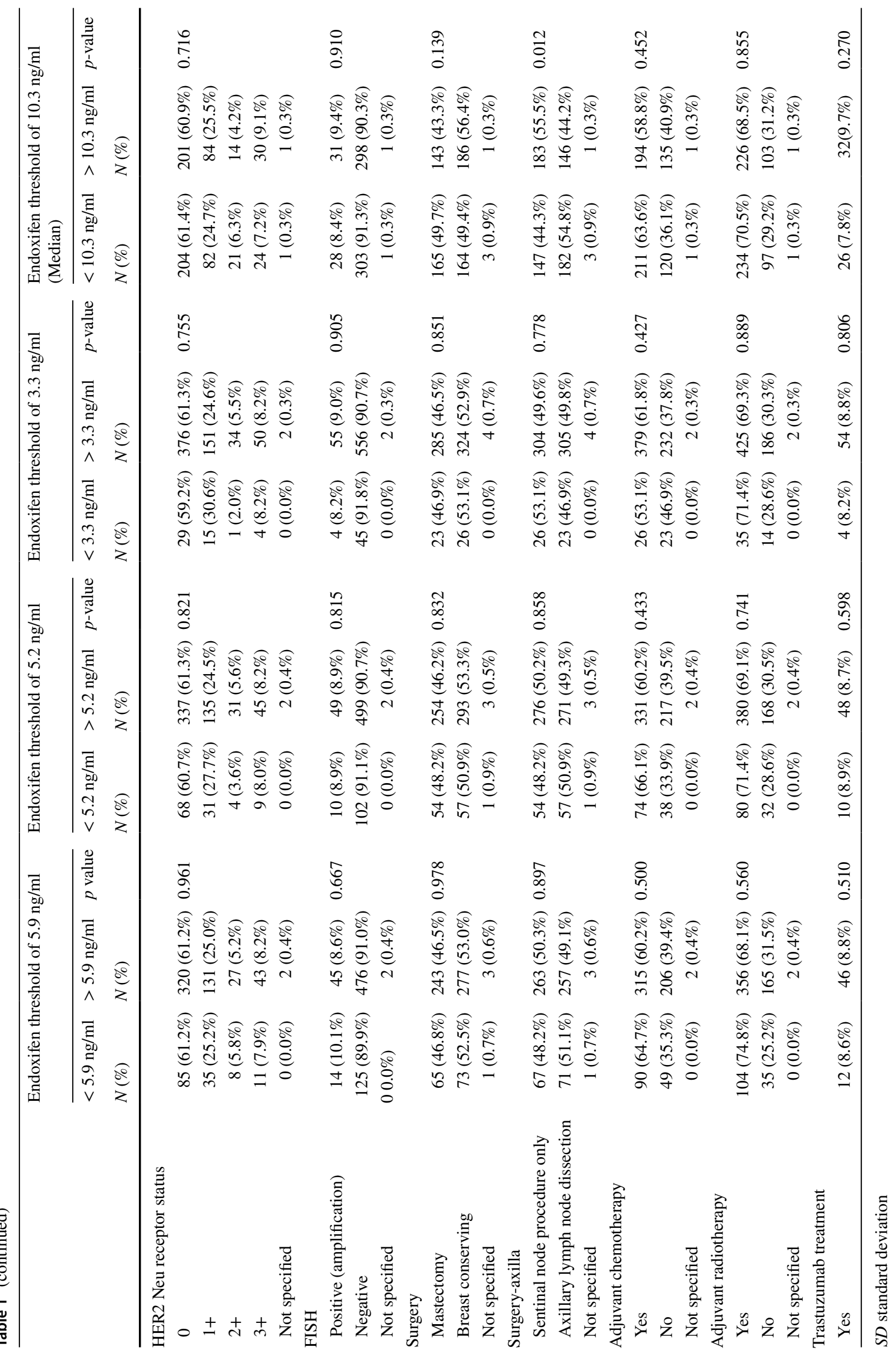


Table 2 Cox proportional hazards ratio model of RFSt

\begin{tabular}{|c|c|c|c|c|c|c|c|}
\hline \multirow[t]{2}{*}{ Endoxifen analysis } & \multirow[t]{2}{*}{$N(\%)$} & \multicolumn{3}{|c|}{ Univariable analysis } & \multicolumn{3}{|c|}{ Multivariable analysis* } \\
\hline & & HR & $95 \% \mathrm{CI}$ & $P$-value & HR & $95 \% \mathrm{CI}$ & $P$-value \\
\hline $\begin{array}{l}\text { Endoxifen** }(\mathrm{ng} / \mathrm{ml}) \\
\quad(\text { continuous variable })\end{array}$ & $662(100)$ & 0.988 & $0.944-1.035$ & 0.613 & 0.985 & $0.938-1.034$ & 0.541 \\
\hline \multicolumn{8}{|c|}{ Endoxifen concentration by quartile } \\
\hline $\mathrm{Q} 1:<6.6 \mathrm{ng} / \mathrm{ml}$ & $165(24.9 \%)$ & 1.000 & Reference & 0.319 & 1.000 & Reference & 0.181 \\
\hline Q2: $6.6-10.3 \mathrm{ng} / \mathrm{ml}$ & $167(25.2 \%)$ & 1.748 & $0.817-3.739$ & 0.150 & 1.879 & $0.864-4.090$ & 0.112 \\
\hline Q3: $10.3-14.1 \mathrm{ng} / \mathrm{ml}$ & $165(24.9 \%)$ & 1.311 & $0.582-2.954$ & 0.513 & 1.272 & $0.553-2.927$ & 0.571 \\
\hline $\mathrm{Q} 4:>14.1 \mathrm{ng} / \mathrm{ml}$ & $165(24.9 \%)$ & 0.951 & $0.403-2.241$ & 0.908 & 0.867 & $0.363-2.069$ & 0.747 \\
\hline \multicolumn{8}{|l|}{ Endoxifen threshold $* *$} \\
\hline$<5.9 \mathrm{ng} / \mathrm{ml}$ & $139(21 \%)$ & 1.000 & Reference & & 1.000 & Reference & \\
\hline$>5.9 \mathrm{ng} / \mathrm{ml}$ & $523(79 \%)$ & 1.382 & $0.652-2.928$ & 0.399 & 1.426 & $0.666-3.053$ & 0.361 \\
\hline \multicolumn{8}{|l|}{ Endoxifen threshold } \\
\hline$<5.2 \mathrm{ng} / \mathrm{ml}$ & $112(16.9 \%)$ & 1.000 & Reference & & 1.000 & Reference & \\
\hline$>5.2 \mathrm{ng} / \mathrm{ml}$ & $550(83.1 \%)$ & 2.391 & $0.863-6.621$ & 0.094 & 2.545 & $0.912-7.096$ & 0.074 \\
\hline \multicolumn{8}{|l|}{ Endoxifen threshold } \\
\hline$<3.3 \mathrm{ng} / \mathrm{ml}$ & $49(7.4 \%)$ & 1.000 & Reference & & 1.000 & Reference & \\
\hline$>3.3 \mathrm{ng} / \mathrm{ml}$ & $613(92.6 \%)$ & 3.508 & $0.485-25.378$ & 0.214 & 2.992 & $0.410-21.822$ & 0.280 \\
\hline \multicolumn{8}{|l|}{ Endoxifen threshold } \\
\hline$<10.3 \mathrm{ng} / \mathrm{ml}$ & $332(50.2 \%)$ & 1.000 & Reference & & 1.000 & Reference & \\
\hline$>10.3 \mathrm{ng} / \mathrm{ml}$ & $330(49.8 \%)$ & 0.803 & $0.472-1.365$ & 0.418 & 0.728 & $0.421-1.258$ & 0.255 \\
\hline
\end{tabular}

*Adjusted for: Her2Neu status, histologic grade and classification, tumour size and nodal stage

**Outcomes presented the original CYPTAM study, and are reported here for completeness [1]. Q1 quartile 1, $Q 2$ quartile 2, $Q 3$ quartile 3, $Q 4$ quartile 4, RFSt relapse-free survival during tamoxifen treatment

\section{Clinical outcome and endoxifen serum concentrations: logistic regression analysis}

To evaluate the concentration effect of endoxifen and RFSt relationship, we adopted a different approach. For this analysis, the probability of relapse (relapse or no relapse) for each patient in the study population was calculated by performing a logistic regression analysis. Thereafter, these calculated probabilities were contrasted against the individual value of endoxifen concentrations of each patient. Interestingly, a decreasing line (illustrated with its $95 \%$ confidence interval) is observed: although the probabilities of relapse are slightly higher in the patients with a low endoxifen concentrations, a slightly lower chance of relapse is observed across the patients with higher endoxifen concentrations. In terms of effect size, the calculated OR was 0.971 (95\% CI 0.923-1.021, $p$ value: 0.248). Although this OR is not statistically significant, a visual representation may suggest a minor concentration-effect relationship for endoxifen levels and probability of relapse. This decrease of the probability of breast cancer relapse by higher endoxifen concentrations might roughly account for $5 \%$ in the probability of breast cancer recurrence. This logistic regression line is presented as Fig. 3.

\section{Tamoxifen discontinuation and endoxifen serum concentrations: logistic regression analysis}

Next, we used an analogous approach to assess the concentration effect of endoxifen concentrations and the probability of tamoxifen discontinuation due to side effects by performing a second logistic regression analysis. To this end, we computed the probability of tamoxifen treatment discontinuation (stopping treatment with tamoxifen or not) for each individual in the enrolled CYPTAM cohort. In the same way, all these probabilities of tamoxifen discontinuation were compared and delineated against the endoxifen concentrations of every patient. In this analysis, the obtained OR was 1.006 (95\% CI $0.961-1.053, p$ value: 0.798). In contrast to the previous analysis, an increasing line is depicted: whilst the probabilities of tamoxifen treatment discontinuation is minimally increased in patients with the highest endoxifen concentrations, a minor lower tamoxifen discontinuation probability is seen among patients with the lowest endoxifen concentrations. A presentation of this illustration is shown in Fig. 4. 

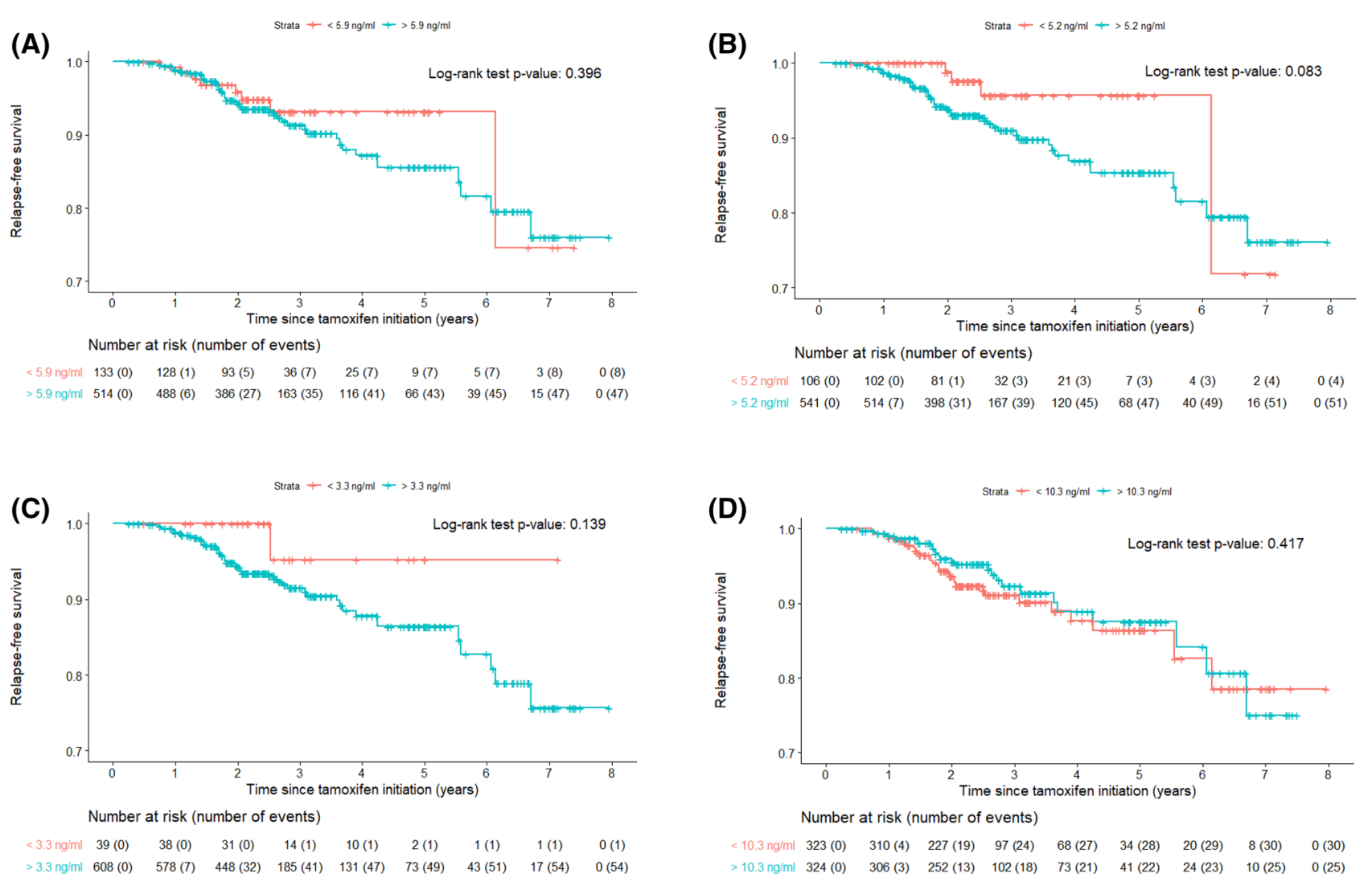

Fig. 2 Kaplan-Meier representations of the proposed threshold for endoxifen concentrations: a $5.9 \mathrm{ng} / \mathrm{ml} ; \mathbf{b} 5.2 \mathrm{ng} / \mathrm{ml} ; \mathbf{c} 3.3 \mathrm{ng} / \mathrm{ml} ; \mathbf{d} 10.3 \mathrm{ng} / \mathrm{ml}$

\section{Discussion}

In this large cohort of early-breast cancer patients receiving tamoxifen, logistic regression analyses suggest a minor exposure-response relation with a slightly decreased risk of relapse and a small increased risk for tamoxifen discontinuation at higher endoxifen concentrations. These observations indicates the existence of a concentration-effect relationship for endoxifen concentrations and the probability of breast cancer relapse (RFSt) however the clinical relevance seems limited. At the same time, using the proposed endoxifen concentration thresholds from the literature $(5.9 \mathrm{ng} / \mathrm{ml}, 5.2 \mathrm{ng} /$ $\mathrm{ml}$ and $3.3 \mathrm{ng} / \mathrm{ml}$ ) and the median endoxifen concentration of $10.3 \mathrm{ng} / \mathrm{ml}$ were not associated with clinical outcome defined as RFSt.

Endocrine therapy with tamoxifen has been the standardof-care for more than 40 years for women in the adjuvant and metastatic setting [25]. In the search of a biomarker to predict tamoxifen efficacy, alternatives such as endoxifen or 4-hydroxy-tamoxifen concentrations have been proposed $[7,10]$. In the case of endoxifen concentrations, the $5.97 \mathrm{ng} /$ $\mathrm{ml}$ threshold of Madlensky and colleagues is considered the most important cutoff point, whilst it is also the most widely used one [7]. However, we believe the application of this concentration in the current practice should be carefully evaluated. In their manuscript, Madlensky et al. did not report the used dose of tamoxifen neither endocrine therapy duration. At the same time, all described survival outcomes, e.g. Cox regression analysis, were analysed as diseasefree survival, which was defined as the time of diagnosis till the time of second breast cancer. Since no additional information regarding tamoxifen exposure was included in their analysis (e.g. dose or therapy duration), this reported endoxifen concentration of $5.97 \mathrm{ng} / \mathrm{ml}$ may not correctly illustrate the impact of the exposure to endoxifen concentration. Another potential remark might be the minor difference in the percentages of recurrences observed across the studied groups (quintiles): while the percentage of recurrence of the lowest group (quintile) was $16 \%$, this rate in the higher groups (quintiles) could be seen as comparable (e.g. recurrence rate in third quintile was $14.7 \%$ ).

Although currently the majority of clinical guidelines recommends at least 5 years of endocrine therapy (either as tamoxifen or as aromatase inhibitor, or any of these combined) $[2,3]$, different strategies, e.g. 2 years vs 5 years of tamoxifen [26], were still suggested to be beneficial during the WHEL study. Consequently, quantifying this putative cutoff point for endoxifen in current antiestrogenic strategies 

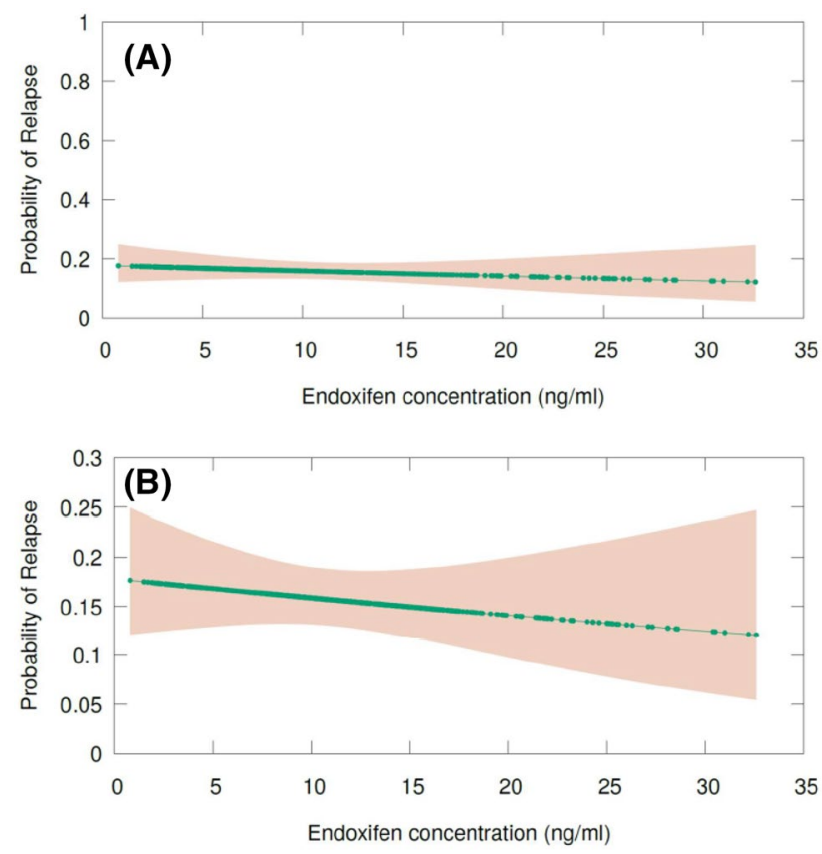

Fig. 3 Logistic regression of the probability of relapse and endoxifen concentrations. a Probability of relapse and endoxifen concentrations (scale of probability $0-1$ ). In this Figure, contrasting the probability of relapse against endoxifen concentrations leads to an almost flat line. b Probability of relapse and endoxifen concentrations (scale of probability $0-0.3$ ). In this Figure, contrasting the probability of relapse against endoxifen concentrations shows a decreasing line

may be extremely difficult to measure. In any case, we did not find any difference in our study when comparing both groups (above vs below $5.9 \mathrm{ng} / \mathrm{ml}$ ) (adjusted HR: $1.426,95 \%$ CI $0.666-3.053, p$ value: 0.361 ). Although the main advantage of Madlensky's study might rely on the high number of included patients (1370 individuals), we also failed to find any association despite of analysing from the exposure to tamoxifen therapy. A possible reason for these outcomes might be due to the use of the term "threshold effect".

Generally, a threshold effect is supposed to be an inflexion mark or level at which a significant variation takes place [27]. As observed in our proposed figure for endoxifen concentration and probability of relapse, around $5.9 \mathrm{ng} / \mathrm{ml}$ [8] or $5.2 \mathrm{ng} / \mathrm{ml}$ [9], or the even lower level of $3.3 \mathrm{ng} / \mathrm{ml} \mathrm{[10],} \mathrm{no}$ changes in the curve of our analysis could be found (Fig. 3). In contrast, we observed a decreasing curve in which higher endoxifen concentrations are related to lower probability of breast cancer relapse, suggesting a concentration effect relationship for endoxifen (Fig. 3). Interestingly, this lower chance of probability (around 5\%) is in line with the main advantage of the use of adjuvant endocrine therapy with tamoxifen in terms of survival outcome [28]. At the same time, we also observed a growing line when contrasting the effect of endoxifen concentrations with the probability of treatment discontinuation with tamoxifen (Fig. 4).
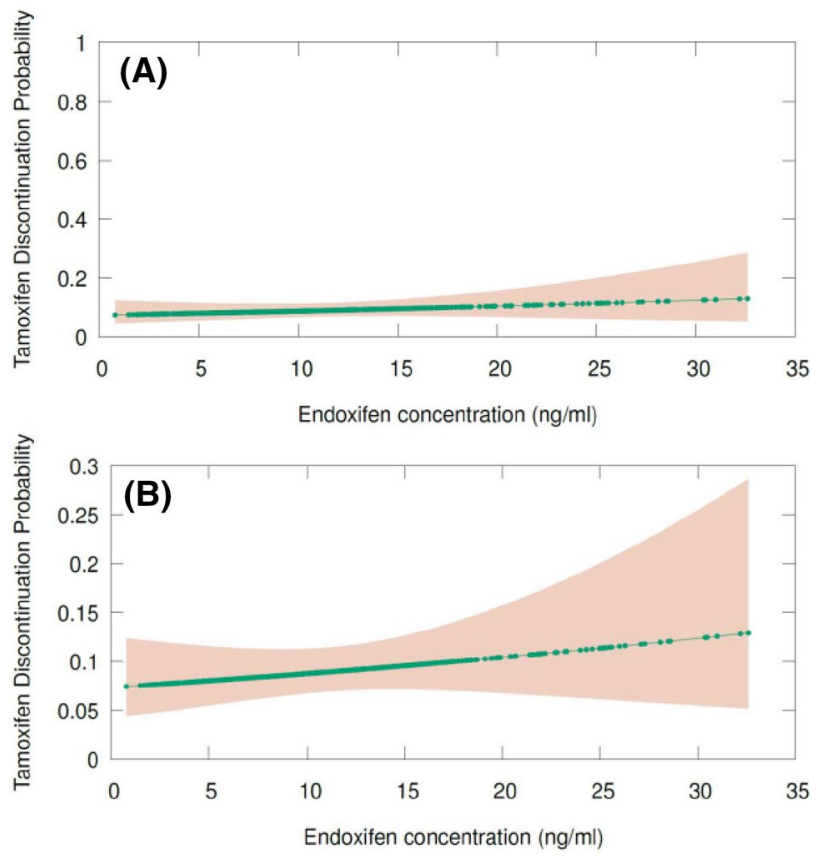

Fig. 4 Logistic regression of the probability of tamoxifen discontinuation and endoxifen concentrations. a Probability of tamoxifen discontinuation and endoxifen concentrations (scale of probability $0-1$ ). In this figure, contrasting the probability of tamoxifen discontinuation against endoxifen concentrations leads to roughly flat line. b Probability of tamoxifen discontinuation and endoxifen concentrations (scale of probability $0-0.3$ )

In our opinion, whilst the hypothesis of lower probability of relapse by higher endoxifen concentrations might be plausible, we also showed that the chance of tamoxifen treatment discontinuation might be higher at higher endoxifen concentrations (Figs. 3 and 4). Consequently, using only endoxifen concentrations as a proxy for tamoxifen efficacy, should be considered cautiously. Owing to the higher endoxifen concentrations (e.g. due to a higher dose of tamoxifen), patients also could tend to have a higher chance of treatment discontinuation due to side effects and therefore, lower adherence, which could potentially lead to treatment failure.

In order to improve the prediction of tamoxifen efficacy, we consider that the anti-estrogenic activity of tamoxifen might not only rely on endoxifen concentrations, but many other variables, e.g. other tamoxifen metabolites and their concentrations, might also be responsible for this difference in relapse. For instance, 4-hydroxy-tamoxifen has an anti-estrogenic activity similar to endoxifen [4], but endoxifen has always been contemplated as the most active metabolite of tamoxifen, since it is found in higher concentrations than 4-hydroxy-tamoxifen [5]. Another example of a difference approach based on the concentrations of other tamoxifen metabolites instead of only endoxifen concentrations was described by De Vries-Schultink and colleagues [29]. Authors created an anti-estrogenic activity 
score and described a new threshold value of 1798 which was associated with recurrence-free survival (HR: 0 0.67; 95\% CI 0.47-0.96). According to the authors, the concordance indices for endoxifen concentrations and this antiestrogenic activity score were similar. Therefore, the theory of an improved clinical outcome based only on endoxifen concentrations may be appealing, but we certainly think tamoxifen efficacy also relies on other factors than endoxifen concentrations.

A potential limitation of our study might be the number of studied patients. In total, we analysed 662 patients of the CYPTAM study, from whom the endoxifen concentrations and survival information were readily available. In our case, the study population may be underpowered. A post hoc power calculation shows that our study may have approximately $30 \%$ of power in order to validate Madlensky's outcomes. This value is lower than the generally accepted $80 \%$ power. However, we also have estimated that nearly 21,500 patients would be required in order to achieve this $80 \%$ power with the observed event rate of roughly $8 \%$ questioning the clinical relevance of the concentration-effect relationship. In the CYPTAM study design, we assumed an HR of 2.0 in order to calculate the required sample size. However, it might have been an overestimation of the effect size and consequently we cannot exclude an association for a $\mathrm{HR} \leq 2$.

Another potential limitation of our study might be the implications for the late breast cancer recurrences and the relatively short follow-up duration time (6.8 years (range 0.33-9.34 years)). Late recurrences due to a purely failure of tamoxifen therapy normally happen after 10-15 years of endocrine treatment with tamoxifen [30]. Consequently, the presented results would mainly apply to early-breast cancer recurrences that occurred during tamoxifen therapy. Ideally, this impact of tamoxifen use on (late) breast cancer recurrences should be evaluated in patients who were only treated with tamoxifen and followed for a long time of at least $10-15$ years.

Another relevant point in our study might be censoring patients at the time of tamoxifen discontinuation due to a switch to an aromatase inhibitor. Since patients were censored at the moment of switch, it might be difficult to strictly separate the effect and the potential therapeutic failure of tamoxifen from aromatase inhibitors due to a potential carryover effect that would still be present during the therapy with aromatase inhibitors. For instance, if an event takes place after only one or two months of the switch to an aromatase inhibitor, it would more likely to think that this event would be due to a failure to tamoxifen therapy rather than an aromatase inhibitor. However, if an event happens after 18 months of aromatase inhibitor use, this event would be more likely explained by an aromatase inhibitor failure than purely a tamoxifen failure. However, tamoxifen might still have a carryover effect that would be present during the therapy with aromatase inhibitors. To this end, a new endpoint was created and named relapse-free survival complete (RFSc), in which the time of aromatase inhibitor was also included [16]. As previously reported [16], we also did not find any type of differences when comparing the different groups based on the endoxifen threshold concentrations of $5.9 \mathrm{ng} / \mathrm{ml}$ (adjusted HR: 1.340; 95\% CI 0.788-2.277; $p$ value: 0.280 ). These results suggest that even if there is a carryover effect of tamoxifen, it might still have a minor impact on the clinical survival. Although censoring patients at this point might have its limitations, our outcomes also have the advantage that they are based on the real-world data and represent the consequences of the therapeutic strategy of tamoxifen and aromatase inhibitors.

Another limitation of our study might be due to the fact that endoxifen concentration levels were only collected and measured once during the first year of tamoxifen treatment, either at enrolment and/or after 2 months of tamoxifen therapy in order to assure steady-state concentrations. Although intra-patient variability of endoxifen concentrations is usually considered as low [31], not measuring endoxifen concentrations at some other points in time might be less informative since endoxifen concentrations might change over time. Potential reasons for variations in concentrations might be new concomitant medication, treatment non-adherence and differences between study data and real-world data.

Although the use of TDM in many other drugs in oncology have shown more promising results [32] in order to predict an improved survival outcome based on the drug concentrations, these outcomes obtained from real-world clinical practice may actually question the added value of TDM of tamoxifen efficacy based only on the endoxifen concentrations. In this case, the observed weak exposure relationship between endoxifen concentrations and clinical outcome has a minor effect and consequently, the potential usefulness of TDM might be interpreted of very limited added value for the clinical setting. Therefore, the remaining question in this ongoing controversy might be a proper study design in order to determine the value of TDM based on the endoxifen concentrations in the clinical daily practice. Recently, a few power calculations based on the Madlensky's study population and the CYPTAM study, suggested that around 1500 patients and 15 years of follow-up would be required in order to adequately investigate this question [33]. In any case, performing such a study might require an important effort. Another approach that could also address this question might be done by combining data of several independent cohorts with available endoxifen concentrations and clinical survival data.

In conclusion, while our analysis shows an endoxifen concentration-effect relationship for relapse and for tamoxifen discontinuation, it does not confirm earlier reported 
threshold values for the use in TDM nor does it allow definition of a novel threshold. These findings suggest there is a limited added value of TDM to guide tamoxifen dosing.

Acknowledgements We would like to thank all the enrolled women in the CYPTAM study, Integraal Kankercentrum Nederland for data management and ZOLEON for its grant.

Author contributions Wrote manuscript: ABS, ARMDJ, JJS, VOD, DL, PN, HG, HG. Designed Research: ABS, ARMDJ, HG, HG. Performed Research: ABS, ARMDJ. Analyzed Data: ABS, ARMDJ, JJS, VOD, HG, HG.

Funding The CYPTAM study was supported by ZOLEON (Stichting ONcologie Holland West) Project 09.09 grant.

Data availability The dataset analysed during the current study is available from the corresponding author Prof. Dr. H.J. Guchelaar on reasonable request. These data are not publicly available due to them containing information that could compromise research participant privacy and consent.

\section{Compliance with ethical standards}

Conflict of interest The authors report no conflicts of interest related to this work.

Open Access This article is licensed under a Creative Commons Attribution 4.0 International License, which permits use, sharing, adaptation, distribution and reproduction in any medium or format, as long as you give appropriate credit to the original author(s) and the source, provide a link to the Creative Commons licence, and indicate if changes were made. The images or other third party material in this article are included in the article's Creative Commons licence, unless indicated otherwise in a credit line to the material. If material is not included in the article's Creative Commons licence and your intended use is not permitted by statutory regulation or exceeds the permitted use, you will need to obtain permission directly from the copyright holder. To view a copy of this licence, visit http://creativecommons.org/licenses/by/4.0/.

\section{References}

1. Jordan VC (2014) Tamoxifen as the first targeted long-term adjuvant therapy for breast cancer. Endocr Relat Cancer 21(3):R235R246. https://doi.org/10.1530/ERC-14-0092

2. Senkus E, Kyriakides S, Ohno S, Penault-Llorca F, Poortmans P, Rutgers E, Zackrisson S, Cardoso F, Committee EG (2015) Primary breast cancer: ESMO clinical practice guidelines for diagnosis, treatment and follow-up. Ann Oncol 26(Suppl 5):v8-30. https://doi.org/10.1093/annonc/mdv298

3. Burstein HJ, Lacchetti C, Anderson H, Buchholz TA, Davidson NE, Gelmon KA, Giordano SH, Hudis CA, Solky AJ, Stearns V, Winer EP, Griggs JJ (2019) Adjuvant endocrine therapy for women with hormone receptor-positive breast cancer: ASCO clinical practice guideline focused update. J Clin Oncol 37(5):423438. https://doi.org/10.1200/JCO.18.01160

4. Lien EA, Solheim E, Lea OA, Lundgren S, Kvinnsland S, Ueland PM (1989) Distribution of 4-hydroxy- $N$-desmethyltamoxifen and other tamoxifen metabolites in human biological fluids during tamoxifen treatment. Cancer Res 49(8):2175-2183
5. Stearns V, Johnson MD, Rae JM, Morocho A, Novielli A, Bhargava P, Hayes DF, Desta Z, Flockhart DA (2003) Active tamoxifen metabolite plasma concentrations after coadministration of tamoxifen and the selective serotonin reuptake inhibitor paroxetine. J Natl Cancer Inst 95(23):1758-1764

6. Hawse JR, Subramaniam M, Cicek M, Wu X, Gingery A, Grygo SB, Sun Z, Pitel KS, Lingle WL, Goetz MP, Ingle JN, Spelsberg TC (2013) Endoxifen's molecular mechanisms of action are concentration dependent and different than that of other antiestrogens. PLoS ONE 8(1):e54613. https://doi.org/10.1371/journ al.pone. 0054613

7. de Vries Schultink AHM, Huitema ADR, Beijnen JH (2018) Therapeutic drug monitoring of endoxifen as an alternative for CYP2D6 genotyping in individualizing tamoxifen therapy. Breast 42:38-40. https://doi.org/10.1016/j.breast.2018.08.100

8. Madlensky L, Natarajan L, Tchu S, Pu M, Mortimer J, Flatt SW, Nikoloff DM, Hillman G, Fontecha MR, Lawrence HJ, Parker BA, Wu AH, Pierce JP (2011) Tamoxifen metabolite concentrations, CYP2D6 genotype, and breast cancer outcomes. Clin Pharmacol Ther 89(5):718-725. https://doi.org/10.1038/clpt.2011.32

9. Saladores P, Murdter T, Eccles D, Chowbay B, Zgheib NK, Winter S, Ganchev B, Eccles B, Gerty S, Tfayli A, Lim JS, Yap YS, Ng RC, Wong NS, Dent R, Habbal MZ, Schaeffeler E, Eichelbaum M, Schroth W, Schwab M, Brauch H (2015) Tamoxifen metabolism predicts drug concentrations and outcome in premenopausal patients with early breast cancer. Pharmacogenomics J 15(1):84-94. https://doi.org/10.1038/tpj.2014.34

10. Helland T, Henne N, Bifulco E, Naume B, Borgen E, Kristensen VN, Kvaloy JT, Lash TL, Alnaes GIG, van Schaik RH, Janssen EAM, Hustad S, Lien EA, Mellgren G, Soiland H (2017) Serum concentrations of active tamoxifen metabolites predict long-term survival in adjuvantly treated breast cancer patients. Breast Cancer Res 19(1):125. https://doi.org/10.1186/s13058-017-0916-4

11. Love RR, Desta Z, Flockhart D, Skaar T, Ogburn ET, Ramamoorthy A, Uy GB, Laudico AV, Van Dinh N, le Quang H, Van To T, Young GS, Hade E, Jarjoura D (2013) CYP2D6 genotypes, endoxifen levels, and disease recurrence in 224 Filipino and Vietnamese women receiving adjuvant tamoxifen for operable breast cancer. Springerplus 2(1):52. https://doi.org/10.1186/2193-1801-2-52

12. Groenland SL, Sanchez-Spitman AB, Moes DJAR, Koolen SL, Dezentje VO, van Erp N, Mathijssen RHJ, Guchelaar HJ, Huitema ADR, Steeghs N (2018) Incidence of clinically significant toxicities in patients with high endoxifen concentrations. Ann Oncol 29:82

13. Helland T, Hagen KB, Haugstoyl ME, Kvaloy JT, Lunde S, Lode K, Lind RA, Gripsrud BH, Jonsdottir K, Gjerde J, Bifulco E, Hustad S, Jonassen J, Aas T, Lende TH, Lien EA, Janssen EAM, Soiland H, Mellgren G (2019) Drug monitoring of tamoxifen metabolites predicts vaginal dryness and verifies a low discontinuation rate from the Norwegian prescription database. Breast Cancer Res Treat 177(1):185-195. https://doi.org/10.1007/s1054 9-019-05294-w

14. Neven P, Jongen L, Lintermans A, Van Asten K, Blomme C, Lambrechts D, Poppe A, Wildiers H, Dieudonne AS, Brouckaert O, Decloedt J, Berteloot P, Verhoeven D, Joerger M, Vuylsteke P, Wynendaele W, Casteels M, Van Huffel S, Lybaert W, Van Ginderachter J, Paridaens R, Vergote I, Dezentje VO, Van Calster B, Guchelaar HJ (2018) Tamoxifen metabolism and efficacy in breast cancer: a prospective multicenter trial. Clin Cancer Res 24(10):2312-2318. https://doi.org/10.1158/1078-0432. CCR-17-3028

15. Takano T, Imamura CK, Tamura K, Saji S, Yamanaka T, Yonemori K, Takahashi M, Tsurutani J, Nishimura R, Sato K, Kitani A, Ueno NT, Mushiroda T, Kubo M, Fujiwara Y, Tanigawara Y (2018) A randomized phase II trial evaluating CYP2D6 genotypeguided tamoxifen dosing in hormone receptor-positive metastatic 
breast cancer: TARGET-1. J Clin Oncol 36(15 Suppl):1046. https ://doi.org/10.1200/jco.2018.36.15_suppl.1046

16. Sanchez-Spitman A, Dezentje V, Swen J, Moes D, Bohringer S, Batman E, van Druten E, Smorenburg C, van Bochove A, Zeillemaker A, Jongen L, Los M, Neven P, Gelderblom H, Guchelaar HJ (2019) Tamoxifen pharmacogenetics and metabolism: results from the prospective CYPTAM study. J Clin Oncol 37(8):636646. https://doi.org/10.1200/JCO.18.00307

17. Brauch H, Schroth W, Murdter T, Schwab M (2019) Tamoxifen pharmacogenetics and metabolism: the same is not the same. $\mathrm{J}$ Clin Oncol. https://doi.org/10.1200/jco.19.00507

18. Goetz MP, Suman VJ, Nakamura Y, Kiyotani K, Jordan VC, Ingle JN (2019) Tamoxifen metabolism and breast cancer recurrence: a question unanswered by CYPTAM. J Clin Oncol. https://doi. org/10.1200/jco.19.00504

19. Braal CL, Beijnen JH, Koolen SL, Oomen-de Hoop E, Steeghs N, Jager A, Huitema AD, Mathijssen RH (2019) Relevance of endoxifen concentrations: absence of evidence is not evidence of absence. J Clin Oncol 37(22):1980-1981

20. Dezentje VO, Opdam FL, Gelderblom H, Hartigh DJ, Van der Straaten T, Vree R, Maartense E, Smorenburg CH, Putter H, Dieudonne AS, Neven P, Van de Velde CJ, Nortier JW, Guchelaar HJ (2015) CYP2D6 genotype- and endoxifen-guided tamoxifen dose escalation increases endoxifen serum concentrations without increasing side effects. Breast Cancer Res Treat 153(3):583-590. https://doi.org/10.1007/s10549-015-3562-5

21. Sanchez Spitman AB, Moes DJAR, Gelderblom H, Dezentje VO, Swen JJ, Guchelaar HJ (2017) Effect of CYP3A4*22, CYP3A5*3, and CYP3A combined genotypes on tamoxifen metabolism. Eur J Clin Pharmacol 73(12):1589-1598. https://doi.org/10.1007/s0022 8-017-2323-2

22. Sanchez-Spitman AB, Dezentje VO, Swen JJ, Moes D, Gelderblom H, Guchelaar HJ (2018) Genetic polymorphisms of 3 '-untranslated region of SULT1A1 and their impact on tamoxifen metabolism and efficacy. Breast Cancer Res Treat. https://doi. org/10.1007/s10549-018-4923-7

23. Teunissen SF, Jager NG, Rosing H, Schinkel AH, Schellens JH, Beijnen JH (2011) Development and validation of a quantitative assay for the determination of tamoxifen and its five main phase I metabolites in human serum using liquid chromatography coupled with tandem mass spectrometry. J Chromatogr B Analyt Technol Biomed Life Sci 879(19):1677-1685. https://doi.org/10.1016/j. jchromb.2011.04.011

24. Sanchez-Spitman AB, Moes DA, Gelderblom H, Dezentje VO, Swen JJ, Guchelaar HJ (2017) The effect of rs5758550 on CYP2D6*2 phenotype and formation of endoxifen in breast cancer patients using tamoxifen. Pharmacogenomics 18(12):11251132. https://doi.org/10.2217/pgs-2017-0080
25. Sanchez-Spitman AB, Swen JJ, Dezentje VO, Moes D, Gelderblom H, Guchelaar HJ (2019) Clinical pharmacokinetics and pharmacogenetics of tamoxifen and endoxifen. Expert Rev Clin Pharmacol 12(6):523-536. https://doi.org/10.1080/17512 433.2019.1610390

26. Machin D, Andersen KW (1997) Randomized trial of two versus five years of adjuvant tamoxifen for postmenopausal early stage breast cancer. J Natl Cancer Inst 89(9):659-660. https://doi. org/10.1093/jnci/89.9.659

27. DcoTEmitCED (2019) Meaning in the Cambridge English Dictionary online. https://dictionary.cambridge.org/dictionary/engli sh/threshold-effect. Accessed 6 Aug 2019 [online]

28. Early Breast Cancer Trialists' Collaborative G (2015) Aromatase inhibitors versus tamoxifen in early breast cancer: patient-level meta-analysis of the randomised trials. Lancet 386(10001):13411352. https://doi.org/10.1016/S0140-6736(15)61074-1

29. de Vries Schultink AH, Alexi X, van Werkhoven E, Madlensky L, Natarajan L, Flatt SW, Zwart W, Linn SC, Parker BA, Wu AH, Pierce JP, Huitema AD, Beijnen JH (2017) An antiestrogenic activity score for tamoxifen and its metabolites is associated with breast cancer outcome. Breast Cancer Res Treat 161(3):567-574. https://doi.org/10.1007/s10549-016-4083-6

30. Pan H, Gray R, Braybrooke J, Davies C, Taylor C, McGale P, Peto R, Pritchard KI, Bergh J, Dowsett M, Hayes DF (2017) 20-year risks of breast-cancer recurrence after stopping endocrine therapy at 5 years. N Engl J Med 377(19):1836-1846. https://doi. org/10.1056/NEJMoa1701830

31. Fotoohi AK, Karim H, Lafolie P, Pohanka A, Ostervall J, Hatschek T, Vitols S (2016) Pronounced interindividual but not intraindividual variation in tamoxifen and metabolite levels in plasma during adjuvant treatment of women with early breast cancer. Ther Drug Monit 38(2):239-245

32. Groenland SL, van Nuland M, Verheijen RB, Schellens JHM, Beijnen JH, Huitema ADR, Steeghs N (2019) Therapeutic drug monitoring of oral anti-hormonal drugs in oncology. Clin Pharmacokinet 58(3):299-308. https://doi.org/10.1007/s40262-018-0683-0

33. de Vries Schultink AH, Dorlo TP, Madlensky L, Pierce JP, Beijnen JH, Huitema AD (2019) Prospective evaluation of therapeutic drug monitoring of endoxifen: feasibility of observational and randomized trials. https://www.page-meeting.org/default.asp?abstr act $=9150$. Accessed 18 Oct 2019

Publisher's Note Springer Nature remains neutral with regard to jurisdictional claims in published maps and institutional affiliations. 